\title{
Megakaryocyte Colony Forming Unit
}

National Cancer Institute

\section{Source}

National Cancer Institute. Megakaryocyte Colony Forming Unit. NCI Thesaurus. Code C121478.

A unit of viable cell concentration defined as the minimum number of hematopoietic stem cells able to produce a detectable colony of megakaryocyte lineage cells. 